\title{
Efficacy of Adding Post-Training Nordic Exercises to Hamstring Injury Prevention Program in Soccer Players
}

\author{
HEND ADEL DORGHAM, M.Sc.; MOHSEN MOHAMED EL-SAYYAD, Ph.D. and \\ AHMED EBRAHIM EL-ERIAN, Ph.D.
}

The Department of Basic Science, Faculty of Physical Therapy, Cairo University

\begin{abstract}
Background: Hamstring injuries represent about $50 \%$ of non-contact football muscle injuries, with recurrence rate 12$33 \%$, even with preventive procedures.

Aim of Study: To investigate the effect of Nordic Exercise post training for the hamstring initial injury prevention.

Subjects and Methods: In this randomly controlled trial study, 34 professional football players randomly assigned into two groups, 17 players in each group, with age range 21-35 years old. Group A (experimental): Subjects performed pre and post training Nordic Hamstring Exercise (NHE) while in Group B (control) they performed only the pre training NHE. The duration of therapeutic intervention in both groups was 12 weeks and was performed beside the normal warming up and cooling down.
\end{abstract}

Method of Evaluation: Arabic version of Australian Football association injury form was used to collect the injuries incidence for each subject in both groups.

Results: At the end of the therapeutic intervention, the mean of total risk time was $116.3 \pm 13.2$ and $117.6 \pm 5.7$ exposure hours for group A and B respectively, the experimental group showed reduction in the total number of injuries by $95 \%$ than last season, also the incidence of initial injury in group A was $92 \%$ less than which in last season while in group B it was $80 \%$ less than last season.

Conclusion: The pre and post NHE was more effective in reducing the initial hamstring injury rates in professional football players than the pre NHE alone.

Key Words: Hamstring injuries - Injury prevention - Eccentric - Pre-Nordic Hamstring exercise - Post-Nordic Hamstring Exercise.

\section{Introduction}

HAMSTRING strain injury is the most common noncontact muscle injury for soccer players, representing two thirds of the thigh muscle strains [1] Having high injury and recurrence rate in the past

Correspondence to: Dr. Hend Adel Dorgham, The Department of Basic Science, Faculty of Physical Therapy, Cairo University
3 decades, occur mainly before the end of each half when fatigue plays a role [2] this could lead to inability to play for cup to 90 days [3], which had a great time and financial loss [4]. The Nordic Hamstring Exercise (NHE) which is eccentric strengthening exercise is one of the most important components of the FIFA $11+$ program proved to decrease the hamstring injuries by $51 \%$ among soccer players per $1000 \mathrm{~h}$ of exposure [5], this effect of NHE could due to increasing of muscle activation, a shift in optimum torque production towards longer lengths, this "injury-protective", as the induced muscle damage leaded to sarcomerogenesis (increased muscle fiber length) allowing it to stretch further, only one $\mathrm{NH}$ training session reported to cause immediate shift $\left(7.7^{\circ}\right)$ in optimum knee flexion torque, which was sustained at 10 -day postexercise [6]. A 10 weeks NH showed $20.8 \%$ fascicle length increase [7].

The percentage of injury prevention risk rate varied and was not all the same level of effectiveness, as applying FIFA 11 + resulted in $20-50 \%$ reduction $[8]$ and it was found that high compliance to the $11+$ led to significant decreased the injury risk by $57 \%$ [9]. Also the percentage of the hamstring injury prevention rates by performing the pre-training $\mathrm{NH}$ varied between studies and varied from 51\% [10], 65-70\% [11], 57-72\% [1]. The elite European soccer premier league reported poor effect with NHE with only $11 \%$ in randomized controlled trials [12]. Recently adding post to pre training FIFA $11+$ prevention program as cooling down program to the normal pre-training FIFA11 + as warming up found to decrease the injury by $82 \%$ of all the lower limb injuries with only compliance $85 \%$ to program [10]. In 2017 it was recommended that future research include medical staff to conduct more effective studies in injury prevention with high compliance rate [5]. Since 
adding the post FIFA $11+$ was effective [10], and it was reported that only post training Nordics (completed in fatigued state) resulted in $1.58 \mathrm{~cm}$ increase in muscle fascicle length after 12 weeks of training [1]. It was difficult to find a study in the literature adding the NHE as a post-training exercise program beside the normal pre-training one, to result in more reduction of hamstring injuries, so there was a need to fill the gap and find a more effective hamstring injury prevention program.

\section{Subjects and Methods}

The study design is a randomized controlled trial as pretest, posttest design, which was conducted in 2018 summer football season on 1 st team sporting football club. Randomly from 5 teams from Alexandria Football Clubs, in Egypt, 1 team was randomly chosen by simple randomization. Thirty four male active professional football players with normal healthy subjects were involved in this study, all the participants were free of any hamstring injury at least for 6 months before applying the protocol. A power analysis was performed to confirm that the sample size was adequate and enough. At 95\% Confidence Interval (CI) the sample size was 34 subject, the power of the study was $80.0 \%$. All players were randomly assigned to one of two groups (A and B) of equal number, using opaque sealed envelopes.

Group I (experimental) included 17 players who performed the NHE as pre and post training program. Group II (control) included 17 players who performed only the NHE as pre training program, both apply the protocol beside traditional warming up and cooling down exercises. The hamstring injury rates of the team was recorded from the history data of the club of the last season. Then these results were compared to the results found after 3 months of interventions in both groups through Arabic injury form. The injury incidence rate, and Injury Risk Ratio (IRR) were calculated for each group. Before enrollment in the study, each player signed an informed consent.

\section{Treatment procedures:}

The program was administrated for 12 weeks, twice per week except the first week was once/ week, as pre training exercise according to Lovell et al., 2017 [1].

Nordic Hamstring exercise: Fig. (1) showed the player starting position in kneeling position, with the torso from the knees upward held rigid and straight. The physical therapist ensures that the player's feet are in contact with the ground throughout the exercise by sitting in her both knees and applying pressure to the player's heels/lower legs. The instruction given to the player to lower his upper body to the ground, as slowly as possible to maximize loading in the eccentric phase. As shown in Fig. (2) hands and arms are used to break his forward fall and to push him back up after the chest has touched the ground, to minimize loading in the concentric phase.

\section{Warming up and cooling down:}

The traditional warming up for $20 \mathrm{~min}$ in the form of Brazilian exercises; in the form of high knee jumps, arm swings, faster high knees, side stepping, upper body rotations, run pace, counter jumps were performed by all participant shared in this study [13]. The normal cooling down: Was done by cold water immersion for 10min [14] and low-intensity aerobic running was the chosen as mode of active recovery from the exercise [15].

\section{Outcome measures:}

The primary outcome of this study was the hamstring injury incidence as initial. Injury incidence was reported in absolute numbers as well as the injury incidence rate for number of injuries per 1000 player hours in matches and training.

Table (2): The NH as post-training program.

Table (1): The NH as pre-training program.

\begin{tabular}{lccccccccc}
\hline Week & $\begin{array}{c}\text { Session } \\
\text { frequency }\end{array}$ & Sets & Repetitions & $\begin{array}{c}\text { Weekly } \\
\text { volume }\end{array}$ & Week & $\begin{array}{c}\text { Session } \\
\text { frequency }\end{array}$ & Sets & Repetitions $\begin{array}{c}\text { Weekly } \\
\text { volume }\end{array}$ \\
\hline 1 & 1 & 2 & 5 & 10 & 1 & 1 & 1 & 2 & 5 \\
2 & 2 & 3 & 5 & 30 & 2 & 2 & 1 & 2 & 10 \\
3 & 2 & 3 & 6 & 36 & 3 & 2 & 1 & 3 & 12 \\
4 & 2 & 4 & 6 & 48 & 4 & 2 & 2 & 3 & 24 \\
5 & 2 & 4 & 7 & 56 & 5 & 2 & 2 & 3 & 28 \\
6 & 2 & 4 & 7 & 56 & 6 & 2 & 2 & 3 & 28 \\
7 & 2 & 4 & 8 & 64 & 7 & 2 & 2 & 4 & 32 \\
8 & 2 & 4 & 8 & 64 & 8 & 2 & 2 & 4 & 32 \\
9 & 2 & 4 & 9 & 72 & 9 & 2 & 2 & 5 & 36 \\
10 & 2 & 4 & 9 & 72 & 10 & 2 & 2 & 5 & 46 \\
11 & 2 & 4 & 10 & 80 & 11 & 2 & 2 & 2 & 40 \\
12 & 2 & 4 & 12 & 96 & 12 & 2 & 2 & & 48 \\
\hline
\end{tabular}




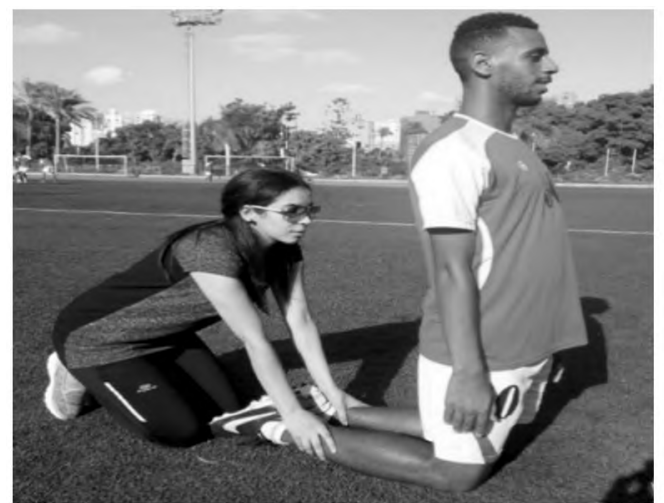

Fig. (1): Illustrating the Nordic Hamstring Exercise therapist and patient starting position.

\section{Results}

34 professional male football players with ages mean $24.3 \pm 3.8$ years old, were assigned into two equal groups, 17 players each (intervention and control). All of them completed the full protocol except 2 players from the intervention group were excluded because of injuries causing absence for more than a week.

Baseline characteristics of the players included in the study were showed in (Table 3 ) as age, weight, height, BMI, and leg dominance, by applying $t$-test and chi-square test, there was no significant difference between the two groups at ( $p>0.05)$, which mean they are homogenous groups.

\section{Exposure time:}

During the 12 weeks program, the players of the two groups of the study had average exposure time to training sessions and playing matches, in which the intervention group had 116.3 \pm 13.2 hours total, and the control group had 117.6 \pm 5.7 hours total, which by applying $t$-test found there was no significant difference between the two groups at 95\% CI (0.65-3.2), at $p>0.05$.

Effect of the intervention on the whole injury incidence:

By applying chi-square test between the two groups it was found that there is a significant increase in the whole injury in control group more than experimental group, as the experimental group had only one injury representing $5.9 \%$ of the injuries while the control had 4 injuries representing $23.5 \%$, with $p$-value $<0.05$.

\section{Effect of the intervention on initial injury:}

Chi-square test was used to compare the hamstring muscle initial injury between both groups, with the end of the intervention protocol in both groups only one hamstring muscle initial injury in

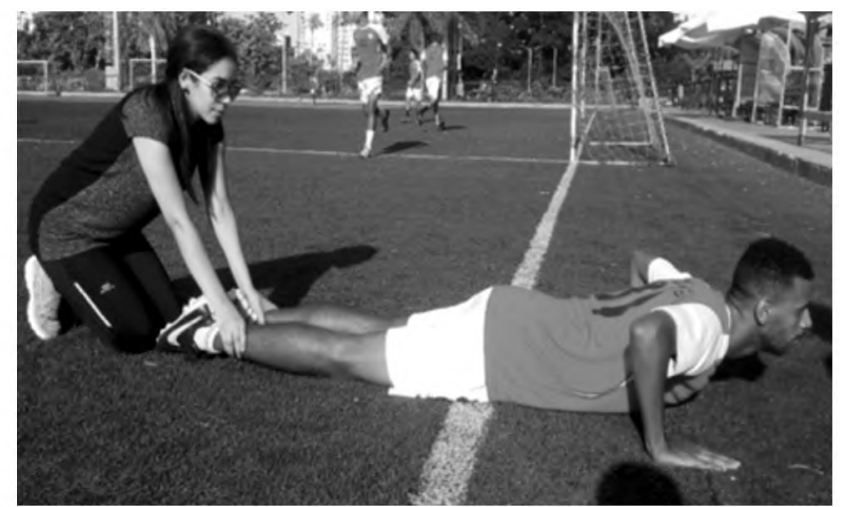

Fig. (2): Nordic Hamstring Exercise ending position.

the group A and 3 in group B (control) were recorded and at $95 \%$ CI $(0.56-1.65)$ and $\chi^{2}(1)=1.133$ the $p$-value was 0.287, as shown in Fig. (3) there was no significant difference between the two groups.

Comparison between the two studied groups and the whole past team regarding initial injuries:

By applying the chi-square test $\left(\chi^{2}=8.25\right)$ at 95\% CI (0.21-0.74), as shown in Fig. (4). It was found that the initial injury in past team injures was $35.1 \%$, this percent was highly significant more than the other two groups of study (experimental and control group) $p<0.05$.

IRR:

By using the following equations:

$$
\begin{gathered}
\text { Injury incidence rate }=\frac{\text { The no. of incidence inj }}{\text { Total time at risk }} \times 1000 \\
\operatorname{IRR}=\frac{\text { Injury incidence in intervention gp }}{\text { Injury incidence in gontrol gp }}
\end{gathered}
$$

There was totally $70 \%$ prevention percentage than the previous season and $92.3 \%$ prevention compared to only the intervention group comparing to the previous season total injuries.

\begin{tabular}{|c|c|c|c|c|c|}
\hline Items & \multicolumn{2}{|c|}{$\begin{array}{c}\text { Group A } \\
\text { mean } \pm \text { SD }\end{array}$} & \multicolumn{2}{|c|}{$\begin{array}{c}\text { Group B } \\
\text { mean } \pm \text { SD }\end{array}$} & $\begin{array}{c}\text { Comparison } \\
p \text {-value }\end{array}$ \\
\hline Age (years) & \multicolumn{2}{|c|}{$24.2 \pm 3.2$} & \multicolumn{2}{|c|}{$24.5 \pm .4 .4$} & 0.412 N.S \\
\hline BMI $\left(\mathrm{kg} / \mathrm{m}^{2}\right)$ & \multicolumn{2}{|c|}{$22.4 \pm 0.4$} & \multicolumn{2}{|c|}{$22.5 \pm 0.2$} & 0.251 N.S \\
\hline Height (m) & \multicolumn{2}{|c|}{$1.80 \pm 0.10$} & \multicolumn{2}{|c|}{$1.90 \pm 0.11$} & 0.093 N.S \\
\hline Weight (kg) & \multicolumn{2}{|c|}{$74.6 \pm 7.2$} & \multicolumn{2}{|c|}{$77.8 \pm 6.0$} & 0.083 N.S \\
\hline Leg dominance: & No. & $\%$ & No. & $\%$ & \\
\hline Right & 16 & 94.1 & 15 & 88.2 & 0.744 N. S \\
\hline Left & 1 & 5.9 & 2 & 11.8 & \\
\hline $\begin{array}{l}\text { Group B: Contro } \\
p \text { is significant } \mathrm{i}\end{array}$ & p. & & $\begin{array}{l}\mathrm{P} \\
\mathrm{N}\end{array}$ & Tot & t \\
\hline
\end{tabular}

Table (3): Demographic data of subjects in both groups. 

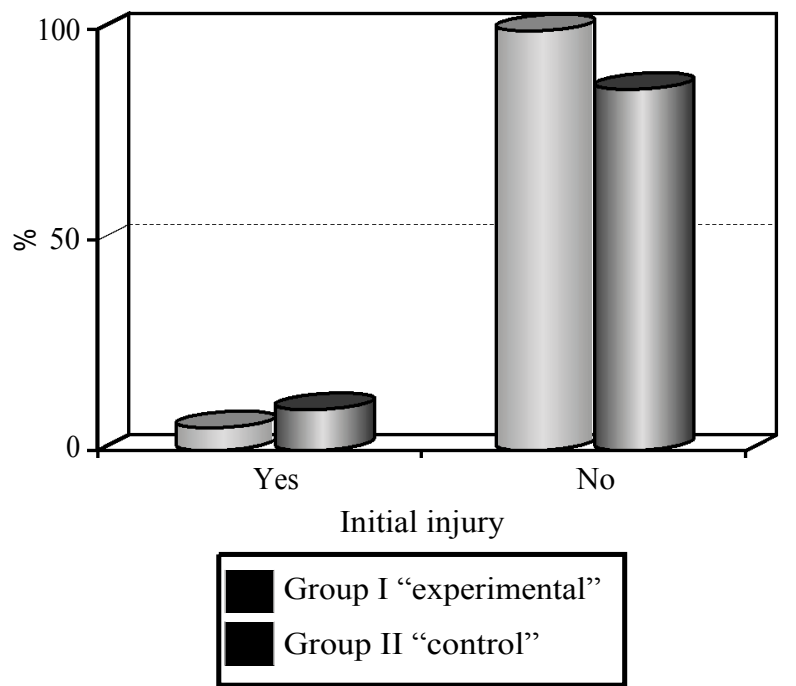

Fig. (3): Comparison between the two studied groups regarding the initial injury.

\section{Discussion}

This randomized control trial was conducted to investigate a more effective eccentric hamstring strength training in the form of $\mathrm{NH}$ program as pre and post training than the traditional pre-training program to reduce more the hamstring injuries incidence rates and recurrent for male professional soccer players.

The Arabic version of Australian Questionnaire to detect injury prevention adoption by the team which considered a limitation for this study [2] was controlled as much as possible in this study by the baseline characteristics of the players included in the study as age, weight, height, BMI, and leg dominance, by applying $t$-test and chi-square test, there was no significant difference between the two groups at $(p>0.05)$, which mean they were homogenous groups.

Also the players of the two studied groups had average exposure time to training sessions and playing matches, in which the intervention group had 116.3 \pm 13.2 hours total, and the control group had 117.6 \pm 5.7 hours total, which by applying $t$ test found there was no significant difference between the two groups at $95 \% \mathrm{CI}(0.65-3.2)$, at $p>0.05$, this similarity in exposure time may overcome the long time (after the full protocol termination) for recording injuries incidence.

Within this limitations, the results of this study revealed that the there was a significant increase in the whole injury in control group more than experimental group, as the experimental group had only one injury representing $5.9 \%$ of the injuries while the control had 4 injuries representing $23.5 \%$,

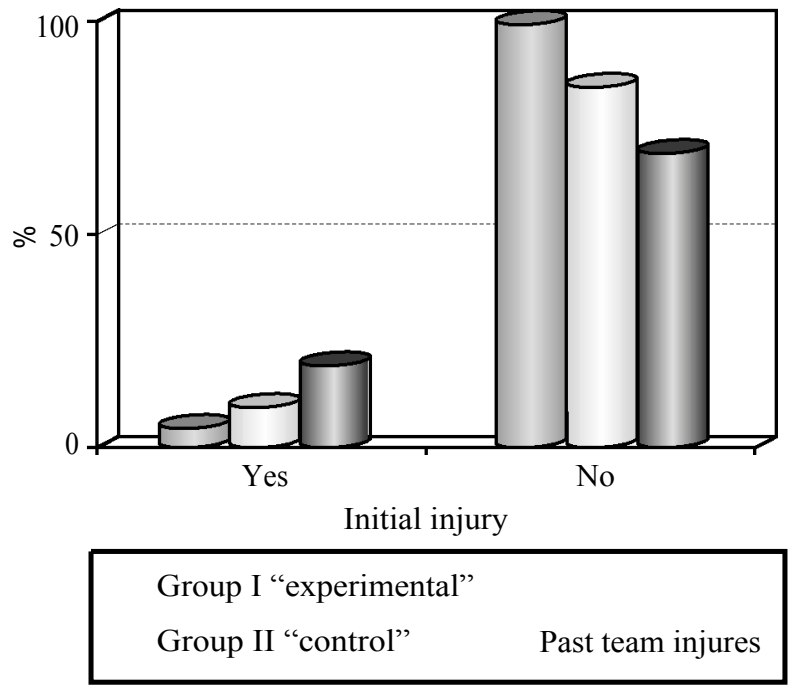

Fig. (4): Comparison between the two studied groups and the whole past team regarding initial injuries.

with $p$-value $<0.05$, also there was no significant difference between the two groups in the hamstring muscle initial injury at the end of the intervention protocol in both group as $p$-value was 0.287 .

This results were in agreement with recent study in 2018, which found that Nordic hamstring is proved to be very effective even with the shortest protocol for 4 weeks [16], but in the present study the intervention protocol duration was 12 weeks which consider the more sufficient duration for muscular adaptation for prevention of hamstring injuries [10], also the current study results were in line with another study which reported that the muscle thickness and fascicle angle of pennation increased more when applying the Nordic hamstring as post training rather than applying it as pre training protocol [1]. Furthermore this results were in agreement with a study which revealed that the pre training protocol only not sufficient for hamstring muscle injuries prevention [17].

The compliance and adherence to the applied protocol was mentioned as a very effective factor in the results obtained and the effectiveness of the protocol [9]. The efficacy of the pre-and posttraining FIFA $11+$ injury prevention program was related to the degree of compliance; that is, the greater the compliance, the greater the reduction in injuries [2]. Compliance with the injury prevention program is very important and can significantly affect the outcomes [10], and so the compliance in the study was the highest as possible and only two players were excluded from the intervention group sample due to injury leading absence more than a week, and the whole other players full completed the whole program as 50 sessions for the interven- 
tion and 25 sessions for control group, and the compliance percentage was the highest compared to the other studies in the same area of research, it was calculated on the basis of information provided by the researcher, it was found to be $100 \%$ for the control group, $98.7 \%$ for the intervention, and total compliance $99.3 \%$, and that was the highest compliance could be achieved. According to this results, a similar study should be conducted on a large number of football teams to provide a wide representation of the data, another study should be done on different professional levels to provide more evidence for the exercise effectiveness in different levels, also further studies using objective tool for assessment of injury should be done.

\section{Conclusion:}

Both applying the $\mathrm{NH}$ as pre training only and pre and post training protocols results in significant decrease in the initial injury rates, so decreasing the days of absence because of this injury, but applying the $\mathrm{NH}$ as pre and post training was more effective in decreasing the whole injury rates compared to applying it only as pre training only in regard to the whole group injury.

\section{Recommendations:}

1- A similar study should be conducted on a large number of football teams to provide a wide representation of the data.

2- A similar study should be conducted on a female football team.

3- Further studies should be done on different professional levels to provide more evidence for the exercise effectiveness in different levels.

4- It is recommended to use another objective tool for assessment of injury and measuring the peak torque of the muscle.

5- It is recommended to apply the whole FIFA 11 + protocol including the $\mathrm{NH}$ and discus the results of injury prevention.

\section{Limitations:}

This study was limited by following factors:

- Questionnaire to detect injury prevention adoption by the team.

- Injury form to collect injuries during the period of applying the protocol.

- Injuries were recorded after 12 weeks (after the full protocol termination).

\section{References}

1- LOVELL R., KNOX M., WESTON M., SIEGLER J., BRENNAN S. and MARSHALL P.: Hamstring injury prevention in soccer: Before or after training? Scand $\mathbf{J}$. Med. Sci. Sports, 00: 1-9, 2017.

2- AL-ATTAR W., SOOMRO N., SINCLAIR P., PAPPAS E., MUAIDI Q. and SANDERS R.: "Implementation of an evidence-based injury prevention program in professional and semiprofessional soccer." Int. J. Sports Sci. Coach., 0 (0): 1-9. (A), 2017.

3- VAN BEIJSTERVELDT A.M., VAN De PORT I.G., VEREIJKEN A.J. and BACKX F.J.: "Risk Factors for Hamstring Injuries in Male Soccer Players: A Systematic Review of Prospective Studies." Scand. J. Med. Sci. Sports, 23: 253-62, 2013.

4- WAN X., QU F., GARRETT W., LIU H. and YU B.: "The effect of hamstring flexibility on peak hamstring muscle strain in sprinting." Journal of Sport and Health Science, 6: 283-9, 2017

5- AL-ATTAR W., SOOMRO N., SINCLAIR P., PAPPAS E. and SANDERS R.: "Effect of injury prevention programs that include the Nordic hamstring exercise on hamstring injury rates in soccer players: A systematic review and metaanalysis". Sports Med., 47: 907-16. (B), 2017.

6- SEYMORE K.D., DOMIRE1 Z.J., VITA1 P.D., RIDER P.M. and KULAS A.S.: "The effect of Nordic hamstring strength training on muscle architecture, stiffness, and strength." Eur. J. Appl. Physiol., 117: 943-53, 2017.

7- BOURNE M., OPAR D., WILLIAMS M., AL-NAJJAR A. and SHIELD A.: "Muscle activation patterns in the Nordic hamstring exercise: Impact of prior strain injury." Scand. J. Med. Sci. Sports, 26: 666-74, 2016.

8- AL-ATTAR W., SOOMRO N., PAPPAS E., SINCLAIR $P$. and SANDERS R.: "How effective are F-MARC injury prevention programs for soccer players? A systematic review and meta-analysis." Sports Med., 46: 205-17, 2016.

9- STEFFEN K., EMERY C., ROMITI M., KANG J., BIZZINI M., DVORAK J., FINCH C. and MEEUWISSE W.: "High adherence to a neuromuscular injury prevention program FIFA $11+$ improves functional balance and reduces injury risk in Canadian youth female football players: A cluster randomized trial." Br. J. Sports Med., 47 (12): 794-802, 2013.

10- AL-ATTAR W., SOOMRO N., PAPPAS E., SINCLAIR P. and SANDERS R.: "Adding a post-training FIFA $11+$ exercise program to the pre-training FIFA $11+$ injury prevention program reduces injury rates among male amateur soccer players: A cluster-randomised trial." Journal of Physiotherapy, 63: 235-42. (C), 2017.

11-VAN DER HORST N., SMITS D., PETERSEN J., GOEDHART E. and BACKX F.: "The preventive effect of the Nordic hamstring exercise on hamstring injuries in amateur soccer players": A randomized controlled trial. Am. J. Sports Med., 43: 1316-23, 2015.

12-ARNASON A., ANDERSEN T., HOLME I., ENGEBRETSEN L. and BAHR R.: "Prevention of hamstring strains 
in elite soccer: An intervention study."Scand. J. Med. Sci. Sports, 18: 40-8, 2008.

13- AYALA F., CALDERÓN-LÓPEZ A., DELGADOGOSÁLBEZ J., PARRA-SÁNCHEZ S., POMARESNOGUERA C., HERNÁNDEZ-SÁNCHEZ S., LOPEZVALENCIO A. and De STE CROIX M.: "Acute Effects of Three Neuromuscular Warm-Up Strategies on Several Physical Performanc Measures in Football Players." PLoSONE Journal, 10: 1371, 2017.

14- MACHADO A.F., FERREIRA P.H., MICHELETTI J.K. ALMEIDA A.C., LEMES I.R., VANDERLEI F.M., JUNIOR J.N. and PASTRE C.M.: Can Water Temperature and Immersion Time Influence the Effect of Cold Water
Immersion on Muscle Soreness? A Systematic Review and Meta-Analysis. Sports Med., 46: 503-14, 2016.

15- MEYER T., WEGMANN M., POPPENDIECK W. and FULLAGAR H.: "Regenerative interventions in professional football." Sport Orthop. Traumatol., 30: 112-8, 2014.

16-ALVARES J.B., MARQUES V.B., VAZ M.A. and BARONI B.M.: "Four weeks of Nordic hamstring exercise reduce muscle injury risk factors in young Adults." Journal of Strength and Conditioning, 32 (5): 1254-62, 2018.

17- NICK VAN DER HORST N.: "Preventing hamstring injuries in football through enhanced exercise and RTP strategies.” Br. J. Sports Med., 0: 1-2, 2018.

\title{
ملى تآثير إضافة النورديك بعد التمهرين لبرنامج منع إصابات عضلة الفخد الخلفية للعيبة كرة القدم الفين
}

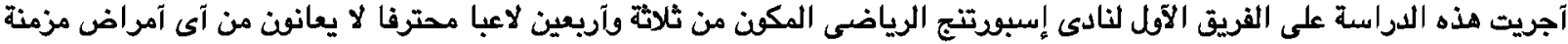

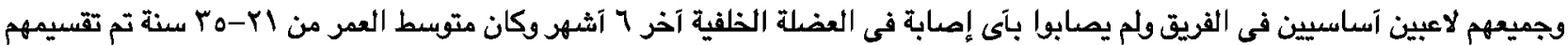

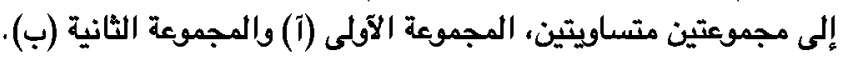

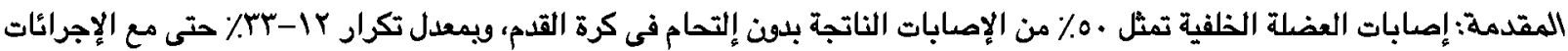 \\ الهدف: إختبار تآثير برنامج النودلك على منع الإصابات الآولية العضلة الخلفية. \\ • المجموعدة الآولى: تتكون من سبعة عشر لاعبا تلقا تمكرين النودل قبل وبعد التمرين مع تمارين الإحماءوالتهدئة. \\ • الهـجموعة الثانية: تتكون من سبعة عشر لاعبا تلقوا تمرين النودك قبل التمرين فقط مع تمارين الإحماءوالتهدئة. \\ طريقة القياس: عن طريق نموذج تقارير إصابات كرة القدم تم تجميع كل الإصابات خلال فترة الدراسة وتم مقارنتها بتلك التى حدثت \\ في الموبيسم السبابق.
}

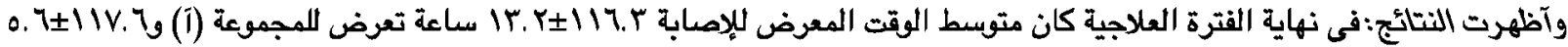

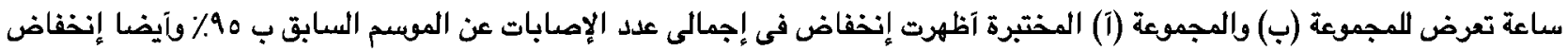

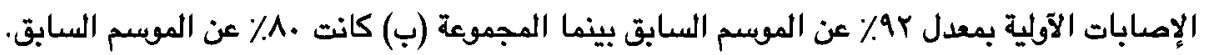

الإستتاج: تطبيق NH قبل بروتوكولات التدريب وبعده آدى إلى إنخفاض كبير فى حدوث الإصابات الآولية للاعبيى كرة القدم المحترفين آكثر من تطبيق البرتوكول قبل التدريب فقط. 